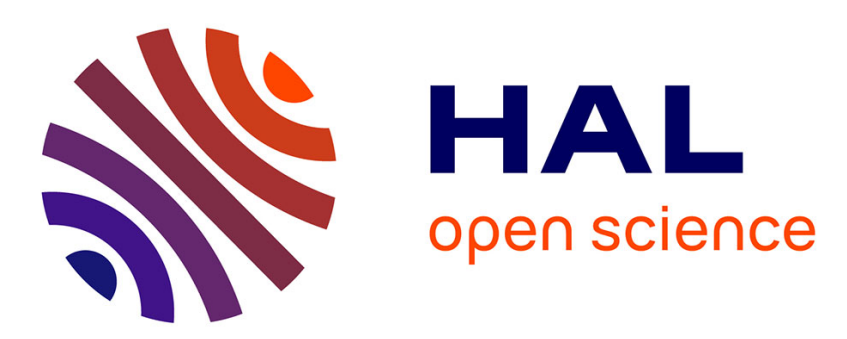

\title{
Estimating the capital stock for the NUTS2 regions of the EU27
}

Ben Gardiner, Sevrin Waights, James Derbyshire

\section{To cite this version:}

Ben Gardiner, Sevrin Waights, James Derbyshire. Estimating the capital stock for the NUTS2 regions of the EU27. Applied Economics, 2011, 45 (09), pp.1133-1149. 10.1080/00036846.2011.613797 . hal00762810

\section{HAL Id: hal-00762810 https://hal.science/hal-00762810}

Submitted on 8 Dec 2012

HAL is a multi-disciplinary open access archive for the deposit and dissemination of scientific research documents, whether they are published or not. The documents may come from teaching and research institutions in France or abroad, or from public or private research centers.
L'archive ouverte pluridisciplinaire HAL, est destinée au dépôt et à la diffusion de documents scientifiques de niveau recherche, publiés ou non, émanant des établissements d'enseignement et de recherche français ou étrangers, des laboratoires publics ou privés. 


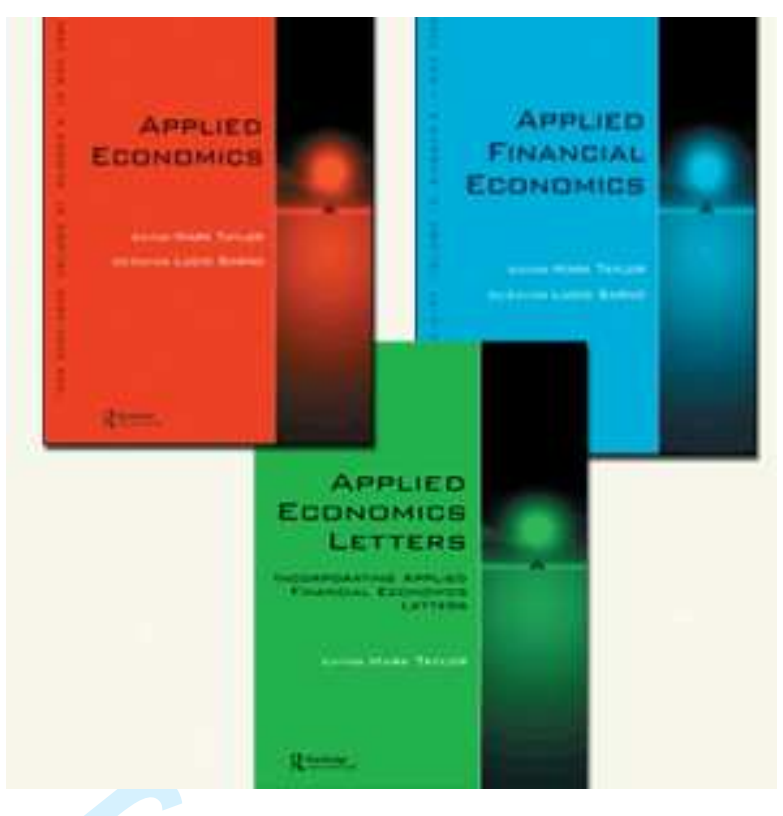

\section{Estimating the capital stock for the NUTS2 regions of the EU27}

\begin{tabular}{|c|c|}
\hline Journal: & Applied Economics \\
\hline Manuscript ID: & APE-2011-0087 \\
\hline Journal Selection: & Applied Economics \\
\hline $\begin{array}{r}\text { Date Submitted by the } \\
\text { Author: }\end{array}$ & 22-Feb-2011 \\
\hline Complete List of Authors: & $\begin{array}{l}\text { Gardiner, Ben; European Commission (JRC-IPTS); Cambridge } \\
\text { Econometrics } \\
\text { Waights, Sevrin; London School of Economics } \\
\text { Derbyshire, James; Cambridge Econometrics }\end{array}$ \\
\hline JEL Code: & $\begin{array}{l}\text { O16 - Financial Markets|Saving and Capital Investment }<01 \text { - } \\
\text { Economic Development }<\text { O - Economic Development, } \\
\text { Technological Change, and Growth, O18 - Regional, Urban, and } \\
\text { Rural Analyses < O1 - Economic Development < O - Economic } \\
\text { Development, Technological Change, and Growth, O47 - } \\
\text { Measurement of Economic Growth|Aggregate Productivity < O4 - } \\
\text { Economic Growth and Aggregate Productivity < O - Economic } \\
\text { Development, Technological Change, and Growth }\end{array}$ \\
\hline Keywords: & Capital Stock, Total Factor Productivity, Regional, Europe \\
\hline
\end{tabular}




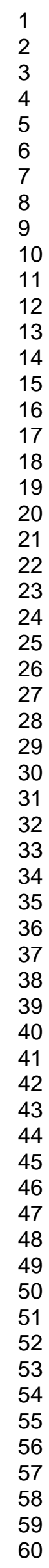

\section{SCHOLARONE ${ }^{m}$ \\ Manuscripts}

7

21

23

24

26

27

29

30

32

33

34

35

36

37

39

40

41

42

44

45

46

47

48

49

51

52

53

54

56

57

58

60

Editorial Office, Dept of Economics, Warwick University, Coventry CV4 7AL, UK 
Estimating the capital stock for the NUTS2 regions of the EU27

\author{
J. Derbyshire ${ }^{a}$, B. Gardiner ${ }^{b, *}$ and S. Waights ${ }^{c}$ \\ ${ }^{a}$ Cambridge Econometrics, Cambridge, CB1 2HS, UK \\ ${ }^{\mathrm{b}}$ Cambridge Econometrics, and the Institute of Prospective Technological Studies (JRC-IPTS), \\ C/Inca Garcilaso 3, 41092 Seville. \\ ${ }^{\mathrm{c}}$ London School of Economics, Houghton St, City of London WC2A 2AE, UK \\ *Corresponding author. Email: ben.gardiner@ec.europa.eu
}

\begin{abstract}
To identify and target lagging regions policy makers require statistics to be produced at regional level. In many instances it is not possible simply to compare regional-level statistics produced by Member State national statistical offices as there is variation in the methods and assumptions used to produce them. Capital stock statistics at the national level have been available for most countries of the EU27 for some time, but statistics at the regional level are absent for almost all countries. Where they do exist the methods used to produce them are not consistent across countries.

This paper assesses the feasibility of producing comparable estimates of the capital stock at NUTS2 regional level for the EU27 and makes some initial estimates. The paper outlines the method and data employed, and the techniques used to fill missing values. The approach is a Perpetual Inventory Method based on that outlined in the OECD Manual on capital estimation, and the data employed were taken from Eurostat or other publicly available sources wherever possible. The paper analyses the robustness of the capital stock estimates produced, as well as their impact on productivity analysis, and suggests how they can be improved in future updates.
\end{abstract}

JEL: O16; O18; O47 


\section{Introduction}

Regional capital stock estimates for Europe are a useful indicator for identifying and targeting lagging regions as part of European cohesion policy. They can also be used as an input in helping to monitor the impact of these policies and to separate regions in need of further support from those which have now developed to a satisfactory level. In addition, there is a need within the academic community for reliable capital stock estimates as they can be used in a variety of ways, such as growth accounting and convergence analysis. Until now, such data have not been available on a consistent and comparable basis, often resulting in academics constructing their own series for particular sub-national analyses (eg Mas et al, 2000 and 2006). In order for regional capital stock statistics to play a role in this process they must be comparable. Not only do most countries not produce regional estimates; those estimates which are in existence are not produced in a comparable way. Indeed, even the capital stock statistics which are widely available at the national level are produced by Member States using idiosyncratic methods and varying assumptions, thus compromising comparability. It is not possible, therefore, simply to disaggregate available national level estimates to regions and compare across the EU.

The remaining sections of this paper are as follows. Section Two describes the outcome of a survey of national statistical offices (NSOs) to ascertain what methodology was being used across Europe to produce capital stock estimates (typically at national level), and reports on the approach adopted by this study, namely the Perpetual Inventory Method based on the OECD Manual (2001, 2009), as well as the underlying assumptions made. The survey of NSOs also reviewed the availability of data inputs necessary to produce capital stock data, and this is reported in Section Three. The data employed to produce the estimates described in this paper were taken from Eurostat or other publicly available sources wherever possible. Section Four presents and analyses results. Finally, in Section Five some concluding remarks are made and 
suggestions for ways in which the estimates can be improved and the method refined in the future.

\section{Methodology}

Survey of European national statistical offices

The survey of national statistical offices showed that all responding countries employ some form of Perpetual Inventory Method (PIM) to produce their capital stock estimates, generally based on the 'standard' PIM outlined in the OECD Manual, 2001 and 2009. There was, however, considerable variability in the assumptions used as the input to this common method. National level estimates are therefore of questionable comparability. It is not possible simply to disaggregate these estimates to the constituent NUTS2 regions and produce comparable regional-level estimates in this way.

For this reason, in order to produce comparable estimates for the NUTS2 regions of the EU it is necessary to employ investment data from the same source (Eurostat) and to employ the same method and assumptions for all regions. This method, and the assumptions that underpin it, are described below. The lack of comparability between the national level capital stock estimates of Member States will still impinge upon the NUTS2 regional estimates presented here. This is because for a number of Member States it was necessary to employ the national-level estimate from the National Statistical Office, disaggregated to the Member State's NUTS2 regions, in order to establish a base-year estimate for 1995. The NUTS2 level investment data from Eurostat is then applied to this base in order to build up a perpetual inventory and a capitalstock estimate for subsequent years. However, over time this base estimate will impinge upon the resulting capital stock estimates diminishingly because of depreciation and retirement. Any lack of comparability introduced through the process of creating an initial base estimate will therefore also diminish over time. This process is described in a subsequent section. 


\section{PIM method}

This section briefly describes the PIM methodology. It begins with the calculation of the gross capital stock, as shown in Equation 1 below.

$$
C S_{t}=\sum_{i=0}^{d-1} I_{t-1}
$$

where $C S_{t}$ is the capital stock in an asset in year $\mathrm{t}$

$$
\begin{aligned}
& I_{t} \text { is investment in year } \mathrm{t} \\
& \mathrm{d} \text { is the assumed service life of the asset }
\end{aligned}
$$

This values the capital at its historic cost (its cost at purchase). To revalue to prices in year $t$ the equation is modified as in Equation 2 below.

$$
C S_{t, t}=\sum_{i-0}^{d-1} I_{t-i} * P_{t-i, t}
$$

where $C S_{t, t}$ is the capital stock in the asset in year $\mathrm{t}$, in prices of year $\mathrm{t}$

$$
P_{t-i, t} \text { is the price in year } \mathrm{t}-\mathrm{i} \text { with year } \mathrm{t} \text { as the price base-year }
$$

The net capital stock is the gross capital stock shown in Equations 1 and 2 minus the accumulated consumption of fixed capital. This is shown in Equation 3 below.

$$
N C S_{t, t}=\sum_{i=0}^{d-1}\left(I_{t-i} * P_{t-i, t}\right) *(1-i / d)
$$

where the inputs are as in Equation 1 and 2, with the addition of $(1-i / d)$ which represents the writing off of consumed capital and where

$d$ is the assumed service life of the asset

and $\quad i$ is the current year the asset is at within its service life (its age)

Under Equation 3 the writing off of consumed capital (depreciation) is linear in nature, with an adjustment in the first and last year of the asset's service life to ensure that write off occurs in 
the middle of the year on average. The method of depreciation (the writing off of consumed capital) therefore doubles up as the method of mortality and removal from the stock. The entire cohort is assumed to be removed from the capital stock immediately when its value has depreciated to zero in the final year of its service life. The assumed mortality function is therefore 'Simultaneous Exit' (OECD Manual, 2001, para.6.51).

Linear depreciation has been shown by Maddison, 1992, and Ward, 1976, to represent a useful approximation of reality when calculating the capital stock. However, the OECD Manual (2001, para.6.64) suggests that Simultaneous Exit is not a very realistic retirement pattern and suggests that bell-shaped patterns, such as the so-called 'Winfrey curves', are more realistic.

In addition to estimates produced using Simultaneous Exit, for this project estimates were also produced using two alternative mortality methods, the Winfrey S-2 function and the Winfrey S3 function. These functions are stated in the OECD Manual (2001, para.6.56) to be two of the most widely employed. Furthermore, the Winfrey S-3 function was shown to be the most commonly employed by EU countries in the survey of EU national statistical offices described in the previous section.

There are eighteen Winfrey curves in total: six 'S' or symmetric curves, six 'L' or left skewed curves and six ' $\mathrm{R}$ ' or right skewed curves. The number in the curve's moniker refers to the relative flatness of the curve with $\mathrm{S} 1$ being the flattest symmetric curve and S6 being the tallest (i.e. most closely distributed around the average service life).

The curves are described as in Equation 4 below.

$F_{T}=F_{0}\left(1-T^{2} / a^{2}\right)^{m}$

where $F_{T}$ is the proportion of the cohort which retires in time period $\mathrm{T}$

$F_{0}$ is the proportion of the cohort retiring at the average retirement age

the parameter $a$ determines how the time periods correspond fractionally to the average service life (e.g. $a=10$ means the time periods are deciles around the average service life)

and the parameter $m$ determines the relative flatness of the function 
The Winfrey S-2 and S-3 curves used to produce estimates as part of this project have retirement from the stock occur according to a symmetrical pattern where the parameters are as in Table 1 below (OECD Manual, 2001, para. 6.56).

Table 1. Parameters for winfrey s-2 and winfrey s-3 curves

\begin{tabular}{|lll|}
\hline & Winfrey S-2 & Winfrey S-3 \\
$\mathrm{F}_{0}$ & 11.991 & 15.610 \\
$\mathrm{~A}$ & 10 & 10 \\
$m$ & 3.7 & 6.902 \\
\hline
\end{tabular}

To summarise, under Simultaneous Exit all assets of the same cohort retire and are removed from the capital stock at the same time once depreciated to zero. All assets are therefore assumed to remain part of the stock for the duration of the average service life (and it may not, therefore, make sense to talk of an 'average' service life when using this approach, since all assets live for this length of time). By comparison, under the Winfrey set of retirement functions the retirement pattern is bell-shaped around the average service life. Assets of the same cohort do not, therefore, all remain part of stock for the entire average service life or all retire at the same time. The average service life is truly an 'average' using this approach then. The time period around the average service life is broken into units, typically deciles, and a probability of retirement is calculated for each decile and applied to the cohort of assets. The retirement is therefore spread around the average service life as shown in Fig. 1 below for an asset with an average service life of five years. Some of the cohort will not make it to the average service life but some will continue as part of the stock beyond this average. In any one decile only a proportion of the cohort is retired whereas $100 \%$ of a cohort, whose value has been depreciated entirely to zero, is retired at five years under Simultaneous Exit. 
Fig. 1. Alternative retirement methods

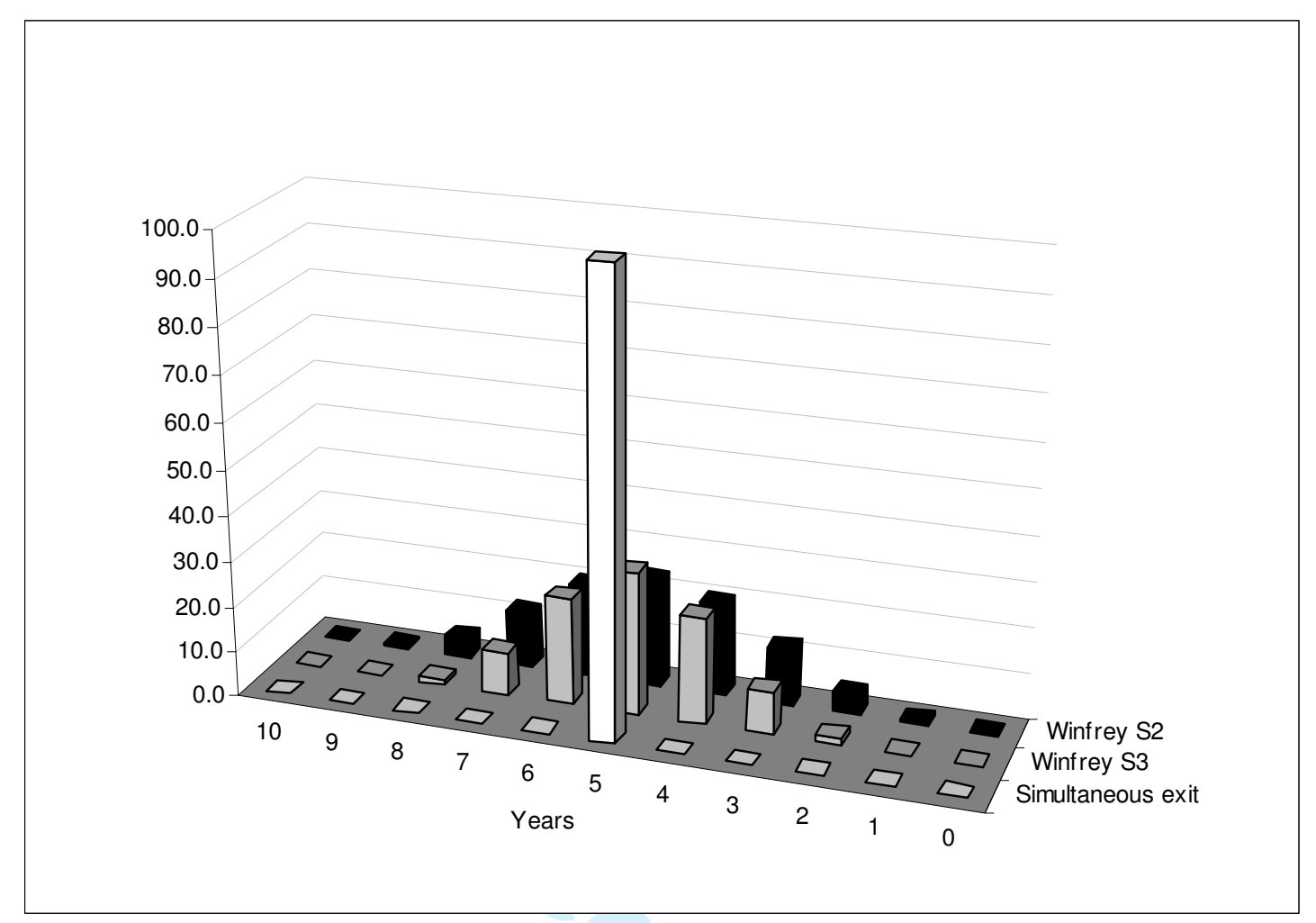

Combining a separate retirement function with depreciation is more complicated than the straight forward way in which depreciation results in Simultaneous Exit in Equation 3 above. The combination of a separate retirement function with linear depreciation is expressed as in Equation 5 below.

$h_{n}=\sum_{T=n}^{T \max } g_{n}(T) F_{T}$

where Tmax is the maximum possible length of service of a particular asset type

$g_{n}(T)$ is the depreciation schedule of an asset with service life $\mathrm{T}$

$F_{T}$ is the probability of retirement at age $\mathrm{T}$

$h_{n}$ is the combined depreciation and retirement function

This shows that the value of the capital stock in time period ' $n$ ' is calculated as the sum of the values of the remaining assets of differing service lives, weighted by their probabilities according to the retirement function. Table 2 shows how $h_{n}$ is calculated for an asset with an 
average service life of 5 years for the Winfrey S2 retirement function combined with linear depreciation. The first two columns represent the retirement function, with the numbers 1-10 in the first column (T) being the asset service life and the numbers in the second column the probability of an asset retiring at this age. The value of the capital stock $h_{n}$ in a particular year ' $n$ ' is calculated as the sum of the values in the column ' $n$ '.

The values in each column of Table 2 are calculated by multiplying the probability of retirement by the depreciation function. An example of the calculations are shown in column 3 $(n=3)$ of the table. Column 3, row 6 corresponds to the value of a 6-year asset after 3 years weighted by the proportion of 6-year assets in the total stock. By summing up all these cells in column 3 the total value of that cohort of capital stock in year 3 is achieved.

Table 2. Combining winfrey s-2 and linear depreciation

\begin{tabular}{|c|c|c|c|c|c|c|c|c|c|c|c|c|}
\hline & Prob. of & & & & & & & & & & & \\
\hline $\mathrm{T}$ & retirement & 0 & 1 & 2 & 3 & 4 & 5 & 6 & 7 & 8 & 9 & 10 \\
\hline 0 & 0 & 0.0 & & & & & & & & & & \\
\hline 1 & 0.5 & 0.5 & 0.0 & & & & & & & & & \\
\hline 2 & 4.6 & 4.6 & 2.3 & 0.0 & & & & & & & & \\
\hline 3 & 12.5 & 12.5 & 8.3 & 4.2 & $0 / 3 * 12.5=0$ & & & & & & & \\
\hline 4 & 20.5 & 20.5 & 15.4 & 10.2 & $1 / 4 * 20.5=5.1$ & 0.0 & & & & & & \\
\hline 5 & 23.8 & 23.8 & 19.1 & 14.3 & $2 / 5 * 23.8=9.5$ & 4.8 & 0.0 & & & & & \\
\hline 6 & 20.5 & 20.5 & 17.1 & 13.7 & $3 / 6 * 20.5=10.2$ & 6.8 & 3.4 & 0.0 & & & & \\
\hline 7 & 12.5 & 12.5 & 10.7 & 8.9 & $4 / 7 * 12.5=7.1$ & 5.4 & 3.6 & 1.8 & 0.0 & & & \\
\hline 8 & 4.6 & 4.6 & 4.0 & 3.4 & $5 / 8 * 4.6=2.9$ & 2.3 & 1.7 & 1.1 & 0.6 & 0.0 & & \\
\hline 9 & 0.5 & 0.5 & 0.5 & 0.4 & $6 / 9 * 0.5=0.4$ & 0.3 & 0.2 & 0.2 & 0.1 & 0.1 & 0.0 & \\
\hline \multirow[t]{2}{*}{10} & 0 & 0.0 & 0.0 & 0.0 & $7 / 10 * 0=0$ & 0.0 & 0.0 & 0.0 & 0.0 & 0.0 & 0.0 & 0.0 \\
\hline & Value(hn) & 100 & 77.3 & 55.1 & 35.3 & 19.5 & 8.9 & 3.1 & 0.7 & 0.1 & 0.0 & 0.0 \\
\hline
\end{tabular}


There are alternatives to the above method for calculating the capital stock, as outlined in the OECD Manual (2001). However, these methods have the disadvantage of requiring a greater number of inputs and assumptions. The method outlined above is relatively simple. Because of this simplicity it requires relatively few inputs and can therefore be applied to all EU countries, even where a scarcity of input data exists.

\section{PIM assumptions}

As is clear from the discussion above, the PIM requires several inputs and assumptions to work. The data requirements and resulting processing (ie issues relating to the base-year capital stock and investment data) are dealt with in the following section. The mortality and depreciation functions have been discussed above. This leaves a brief discussion on average service lives.

A Canadian study, referred to in the OECD Manual, 2001, para. 6.42, but not cited, varied average service life estimates for asset types by $+/-50 \%$ and found that increasing average service life estimates by $50 \%$ results in a $40 \%$ increase in the eventual capital stock estimate. A similar effect results from decreasing service life estimates by the same amount. This study drew the conclusion, however, that most service life assumptions are not likely to show this degree of error. Service life estimates are likely to be wrong by no more than $10 \%$. Nevertheless, even this margin of error means that capital stock estimates are likely to have an error margin in the range $+/-8 \%$.

Service life data were collected from the national statistical agencies in whatever asset classification they had used in their calculations. The results for each country were collated, and a histogram showing the frequency of each value (for individual assets) was created. Some work was also undertaken to evaluate how the NSOs arrived at their average service life values. Many NSOs used a combination of methods. For example, NSOs that use tax lives as a starting point for their estimates recognise that tax lives are deliberately under-estimated in order to encourage investment, and so the NSOs subsequently increased the estimates using expert evaluation. In most cases service-life assumptions are arrived at either by use of a survey (the 
most stringent approach) or through the use of expert evaluation, rather than by simply adopting the values used by another country.

Based on the survey carried out, for the asset types for which capital-stock estimates are produced in this study the following service lives are assumed:

- $\quad$ Metal products \& machinery: 14 years

- Transport equipment: 18 years

- Housing construction: 68 years

- $\quad$ Other construction work: 50 years

- 'Other' assets: 38 years

Straight-line or 'linear' depreciation is employed to depreciate and retire assets from the stock in the main database. In addition, estimates have been produced based on simultaneous exit and two alternative methods, the Winfrey S2 and Winfrey S3 retirement functions, and within these calculations the above values have been used as true average service lives.

\section{Data}

As mentioned previously, the two main data requirements to calculate capital stock using the PIM are a base-year estimate and an investment (gross fixed capital formation) series. Both types of indicator must be available at equivalent levels of disaggregation in order to calculate the required capital stock detail. In addition, if real and nominal calculations are required, as is usually the case, price indices are also necessary.

\section{Data disaggregation}

The dimensions of analysis quickly became apparent from the results of the data survey that was undertaken. The regional (NUTS2) dimension was a focus of the study and so already 
given. The time period of analysis was 1995-2007. The sectors/activities covered were Agriculture, Industry, and Services. Table 3 describes the asset classification as this requires most detail.

Table 3. Classification of asset types

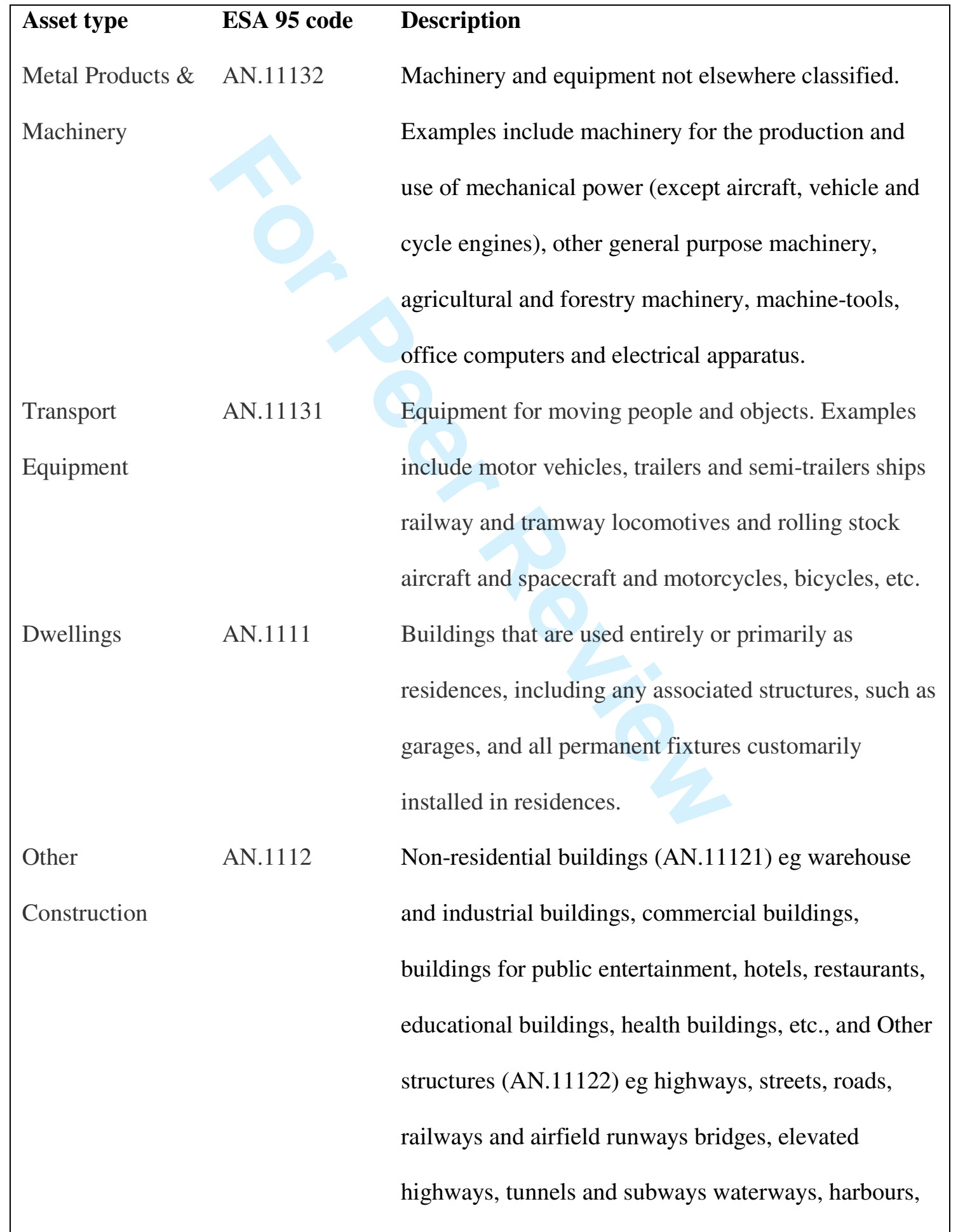


Other Assets

AN.112,

AN.1114

\begin{abstract}
Description
dams and other waterworks long-distance pipelines, communication and power lines local pipelines and cables, ancillary works constructions for mining and manufacture and constructions for sport and recreation.
\end{abstract}

Intangible fixed assets (AN.112) consists of mineral exploration (AN.1121), computer software (AN.1122), entertainment, literary or artistic originals (AN.1123) and other intangible fixed assets (AN.1124), defined as new information, specialised knowledge, etc., not elsewhere classified, whose use in production is restricted to the units that have established ownership rights over them or to other units licensed by the latter. Cultivated asset (AN.1114) includes livestock for breeding, dairy, draught, etc. and vineyards, orchards and other plantations of trees yielding repeat products that are under the direct control, responsibility and management of institutional units.

\section{Data availability}

Capital stock data. At national level, the EU KLEMS database contains capital stock estimates by the required asset and industry disaggregation for many of the required countries. Therefore, since the KLEMS database was using harmonisation procedures to ensure the data are on a comparable basis, these base year estimates were adopted wherever available. Where the 
country in question was not covered by the EU KELMS database, national sources were used. Where national data were not available, alternative filling in mechanisms were used as described below.

EU KLEMS data are only available at the national level and therefore other data sources were required to produced estimates at the regional level. If there was no NUTS2 data available from any source, then a scaling method based on GVA was used, ie the ratio of capital stock in each industry to GVA in that industry was calculated for each asset type at the national level and then applied to GVA by industry at the NUTS2 level.

Investment data. At the national level, Eurostat produces GFCF estimates for the EU27 broken down by asset type and industrial sector. The GFCF data by industry are divided into categories according to the industry in which the assets are being used as means of production. Industrial breakdown and asset type breakdown are published separately by Eurostat, meaning that GFCF for each industry are not available with an asset type breakdown or vice versa. Other European sources of data include the AMECO database, which has national totals.

At regional level, Eurostat has investment data broken down by industry in current prices only, with incomplete coverage and with no disaggregation by asset type. For most countries, there are at least some data by industry for every NUTS2 region, although not for the whole time period required. For the entire EU27, 71\% of the totals figures and $68 \%$ of the figures by industry are available at NUTS2 level for the period 1995-2004. This means that for the required period of $1995-2007$ there were $53 \%$ of the totals data and $54 \%$ of the data by industry.

Data filling-in mechanisms

The following section describes the methodology for producing GFCF estimates by asset, by industry and total from the available raw data for each Member State and region. 
Investment data. Eurostat data were used wherever possible. If Eurostat data were present but not complete, an investment-ratio approach or investment-output scaling approach was used to complete the data series. If Eurostat sources were not available at all, data from the appropriate national statistical office were used. As a last resort, if GFCF data are not available from Eurostat or from the relevant national statistical office then the investment or investment-output ratios of a similar country are used to produce the estimates and the ratio of regional output to national output is used to split the total investment of the nation.

For creating NUTS2 GFCF by industry, the ratio of industry output to total output in the region was used. For creating NUTS2 GFCF by asset, the asset investment ratios of the nation were used to split total investment for the NUTS2 region.

The gaps in the national GFCF by asset type were filled using a similar concept to the investment-output ratios approach. Instead of finding the ratio of investment in an asset type to total GVA it was decided that a better measure to use would be the ratio of investment in an asset type to total investment. These investment ratios were calculated for both current and constant prices and then filled according to the same procedure as with the investment-output ratios. However, there are some countries that had no data by asset type in constant prices. This was because there were no price deflators by asset available for these nations. In these cases price deflators were taken for the country as a whole and applied these to the investment data by asset to produce data in constant prices. Finally, in cases where there are no data for either constant or current prices and no data are available from their national statistical office then investment ratios by asset of a similar country have been applied to total GFCF.

For the NUTS2 regions, there were no raw data by asset type. The data were created by assuming that the asset investment ratios calculated for the nations could be applied to total investment for the NUTS2 regions. This was done for both current and constant prices.

Base year capital stock. For eleven countries capital stock estimates have recently been produced as part of the EU KLEMS project. For the remaining countries the base-year has been constructed in other ways, usually based on capital stock estimates produced by the national 
statistical office. Where no KLEMS or NSO data were available, the option of last resort was to construct the base-year estimate based on the output-capital ratio of a 'similar' country for which a capital stock estimate for 1995 is in existence. It was only necessary to take this option for three countries: Malta, Bulgaria and Greece. The base-year estimate for Bulgaria was based on the capital stock in existence in Romania in 1995, re-estimated to the size of the Bulgarian economy based on the output-capital ratio in Romania. The base-year capital stock for Malta was similarly based on that for Cyprus. The estimate for Greece was based on an average of that for Italy and Spain.

Over the long term calculating the base-year capital stock in this fashion for these three countries will have a limited impact upon the estimates constructed because the inaccuracy introduced will, over time, be slowly eliminated from the stock through retirement and depreciation. However, over a relatively short time-span the inaccuracy introduced as part of this process will have a significant impact upon the results achieved for these three countries. The results for these three countries should therefore be treated with caution.

To some extent this is also true of Latvia because the Latvian national statistical office currently publishes a national capital stock estimate for 2007 only. Since there is only one year of data there was no basis on which to extrapolate back to 1995. This extrapolation was therefore carried out using the growth rates of the Lithuanian capital stock estimates from the Lithuanian national statistical office. Indeed, a number of countries had published capital stock estimates at the national level for recent years but not stretching back as far as 1995. In these cases the estimates were extrapolated back to create the base-year estimate.

For the majority of countries, and all of those for which the EU KLEMS database was used as a source, estimates on which to create the base-year were only available at the national level. The ratio of capital stock in each industry to GVA in that industry was calculated for each asset type at the national level and then applied to GVA by industry at the NUTS2 level.

\section{Results}


Following the lengthy stages of data survey, collection, processing and filling-in mechanisms, the creation of the capital stock series was a relatively straightforward/mechanical process. The purpose of this section is to examine the robustness of the capital stock estimates, their usefulness as an input to analyses of cohesion policy, and the expediency of the approach used to create them more generally.

The analyses start with an examination of the base year capital stock and capital-output ratios at national level. A comparison against existing regional studies is also made, namely that made in Spain by Mas et al, 2006. The general picture of capital stock and capital-labour ratios are then examined across Europe. Finally, some basic total factor productivity calculations are made, and compared against labour productivity, to assess the difference that including capital makes to such productivity calculations.

It should be noted that the statistics mentioned are those created using the Simultaneous Exit retirement function. Estimates were also created using two alternative retirement functions, the Winfrey S2 and Winfrey S3 functions, but these are not examined here.

Base year capital stock (national level)

Table 4 compares the estimates produced at the national level as part of this study with those produced by the relevant NSO or by EU KLEMS. The final two columns of Table 4 compare these results with NSO or EU KLEMS estimates for a mid-year (2001) and the last year for which comparison is possible, which varies by country (because the last year for which estimates are available varies by NSO). For a small number of countries there is no estimate available from the NSO or EU KLEMS for either the mid-year of 2001 or for the end year, or for both. Where this is the case N/A has been entered in the table. Where the comparison can be made, Table 4 shows the 2001 estimate and end year estimate for each Member State to be similar to that produced by the NSO or EU KLEMS. 
Table 4. Comparison of national-level base-year estimates

\begin{tabular}{|c|c|c|c|}
\hline \multirow[t]{3}{*}{ Country } & Start period (1995) & Mid-period (2001) & End period* \\
\hline & & Calculated value / & Calculated value / \\
\hline & billions of euros & NSO or EU Klems value & NSO or EU Klems value \\
\hline AT & 626.2 & 1.07 & 1.08 \\
\hline $\mathrm{BE}$ & 532.3 & 1.04 & 1.06 \\
\hline$B G$ & 20.7 & $\mathrm{n} / \mathrm{a}$ & $\mathrm{n} / \mathrm{a}$ \\
\hline CY & 16.6 & 1.14 & 1.10 \\
\hline $\mathrm{CZ}$ & 186.3 & 1.04 & 1.05 \\
\hline DE & 6213.8 & 1.06 & 1.05 \\
\hline DK & 544.5 & 1.04 & 1.03 \\
\hline EE & 10.6 & 0.76 & 0.88 \\
\hline ES & 1656.2 & 1.00 & 0.99 \\
\hline $\mathrm{FI}$ & 316.9 & 1.05 & 1.06 \\
\hline FR & 3335.9 & 1.10 & 1.12 \\
\hline GR & 314.8 & $\mathrm{n} / \mathrm{a}$ & $\mathrm{n} / \mathrm{a}$ \\
\hline $\mathrm{HU}$ & 260.8 & 0.81 & 0.85 \\
\hline IE & 112.0 & 1.14 & 1.26 \\
\hline IT & 2382.2 & 1.10 & 1.13 \\
\hline LT & 24.0 & $\mathrm{n} / \mathrm{a}$ & 1.18 \\
\hline LU & 54.7 & 0.92 & 0.89 \\
\hline LV & 58.5 & $\mathrm{n} / \mathrm{a}$ & 1.13 \\
\hline MT & 6.1 & $n / a$ & $\mathrm{n} / \mathrm{a}$ \\
\hline $\mathrm{NL}$ & 1061.5 & 1.07 & 1.07 \\
\hline PL & 352.7 & 1.60 & 1.57 \\
\hline PT & 183.9 & 1.06 & 1.05 \\
\hline RO & 63.8 & 1.35 & 1.13 \\
\hline SE & 416.1 & 1.06 & 1.06 \\
\hline SI & 21.3 & 1.33 & 1.40 \\
\hline SK & 115.2 & $n / a$ & 1.26 \\
\hline
\end{tabular}




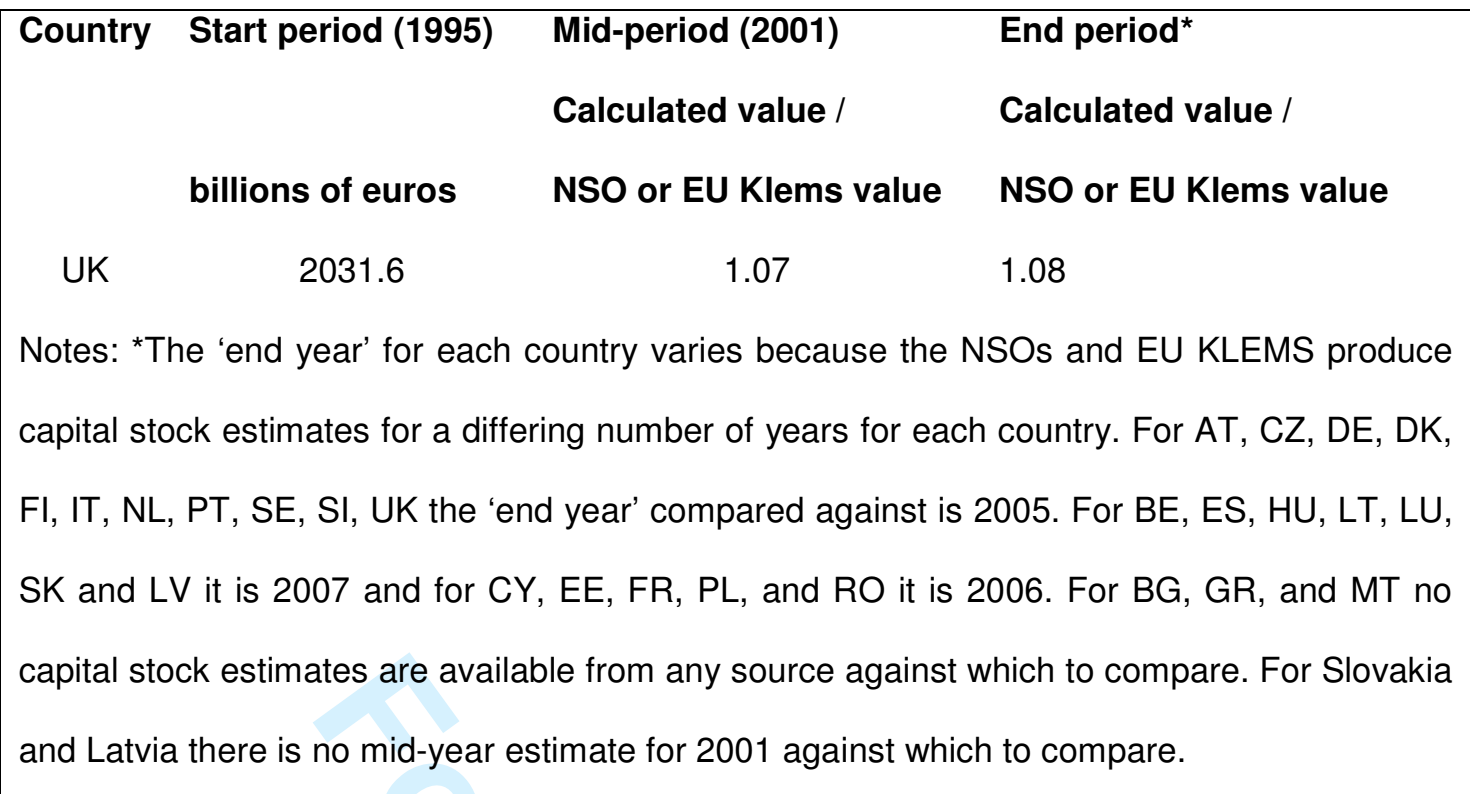

From an initial examination of Table 4 the values of the base-year capital stock in 1995 are broadly as expected given the size of each economy (ie the value of its GDP) and the level of development (GDP per capita and sectoral structure). However, a useful way to further check the robustness of the initial base-year estimates for 1995, to which the perpetual inventory used to produce estimates for subsequent years is applied, is to calculate a capital-output ratio for each country. Capital-output ratios for each Member State for 1995 are shown in Fig. 2. However, it is useful firstly to consider the factors which may lead to a relatively high or low capital-output ratio before comparing with Fig. 2 to see if expectations in this regard are met and whether, therefore, the base-year estimates for 1995 can be considered more or less robust. In relative terms, the size of the capital stock in relation to output is a function of many different factors. Neo-classical growth theory, for example, implies that it will be related to the level of economic development.

Neo-classical growth theory implies that the returns to capital diminish at a rate which depends upon the amount of capital already in existence, see Aghion and Howitt, 1999. Because these returns diminish the incentive to save declines over time and economies head towards a 'steady state' where savings offset but do not exceed the depreciation of capital and the capital stock therefore remains stable (ibid.). This implies convergence as the capital stock will grow at a 
faster rate in less developed economies because they will be further from this steady state and the returns to capital, and therefore the incentives to investing in it, will be greater.

However, while this neo-classical theory implies a faster rate of growth for capital (and output) in less developed economies and therefore convergence, it also implies that the capital-output ratio of more advanced economies will be higher because they will be nearer to the 'steady state'. According to neo-classical theory the more advanced economies of Western Europe should therefore be expected to have a higher capital-output ratio than the less advanced economies in Eastern Europe. Some 'within country' variation would be expected for the same reason. For example, it might be expected that the more developed northern regions of Italy to have a higher capital-output ratio than the less developed southern regions, similarly the western compared to eastern regions of Poland.

Beyond this neo-classical view, there are other factors which are likely to impact upon the capital-output ratio observed for European countries and regions. The capital-output ratio of a region can depend upon its industrial structure and the nature of demand for its products. If the region's industrial structure is skewed towards manufacturing then the capital-output ratio is expected to be relatively large, but even more so if the type of manufacturing tends to be the production of technologically advanced goods for large global markets or energy-related involving machinery for extraction or processing, eg oil sector.

When it comes to services, however, the size of the capital stock in a region is likely to relate to the presence of large agglomerations as services firms tend to be more focussed on the supply of local markets. This suggests a higher capital-output ratio in, for example, the regions containing London, Paris, Berlin, Warsaw and other major cities, as well as in the surrounding regions. More peripheral regions would be less expected to have large capital-output ratios in services.

A further factor likely to influence the capital-output ratio of European regions is the cost of inputs other than capital, in particular labour. There is less incentive to substitute labour with capital if the cost of labour is relatively low. Wages are obviously much lower in Eastern compared to Western European regions and also in Southern compared to Northern European 
regions. The incentive to investment in capital is therefore lower in these regions than it is in Western Europe where wages are considerably higher.

In sum, most of the factors that influence the capital-output ratio imply a distinction between the east and west and north and south of Europe. This is the obvious implication of neoclassical theory as it implies that the less developed countries to the east and south will be further from the 'steady state' and will therefore have less capital in place (though their stock would be expected to be growing more quickly). This is also the implication of the other factors influencing the size of the capital stock discussed above, with the possible exception of industrial structure as one might expect Eastern European countries to have larger manufacturing sectors.

However, when a capital-GDP ratio is obtained for 1995, as shown in Fig. 2, there are some outliers among the New Member States (Latvia, Slovakia and Hungary) which run contrary to the general expectation of a larger capital stock in the more developed Member States to the west. For these countries the capital-output ratio is considerably higher than for the other European countries. In addition, while the results for Slovenia and Romania conform to the expectations outlined above in that their ratios are lower than those of the Western European countries, they probably also represent outliers as their ratios appear a little too low relative to other Eastern European countries. This is especially true of Slovenia which is one of the more advanced Eastern European economies.

These anomalous results no doubt reflect the quality of the data for the early 1990s and, in particular, the need to extrapolate back the baseline capital stock from more recent estimates for these countries as their NSOs do not currently produce estimates for as far back as 1995. This was not necessary for the other Member States. More broadly, the weighted average EU capital-output ratio is about 3 according to the base-year estimates for 1995 shown in Fig. 2, and this provides some reassurance of the relative robustness of these base-year estimates. Estimates of the capital-output ratio for 2002 produced by NIESR, 2002, imply that Germany's ratio was just greater than 3, France's was slightly lower than this at about 2.7 and the UK's was lower still at 2.3. This is similar to what can be seen for 1995 in Fig. 2. For the majority of 
Member States then, excluding the obvious outliers highlighted above, the 1995 base-year estimate is considered to be sufficiently accurate. This provides some reassurance that the estimate for 1995, to which the perpetual inventory method described in section two is applied to produce estimates for subsequent years, is more or less robust for most countries. The results for those countries for which it is clearly inaccurate should be treated with caution, although it is also important to remember that the influence of the base-year estimate weakens over time because of retirement and depreciation.

Fig. 2. Base year capital-output ratio

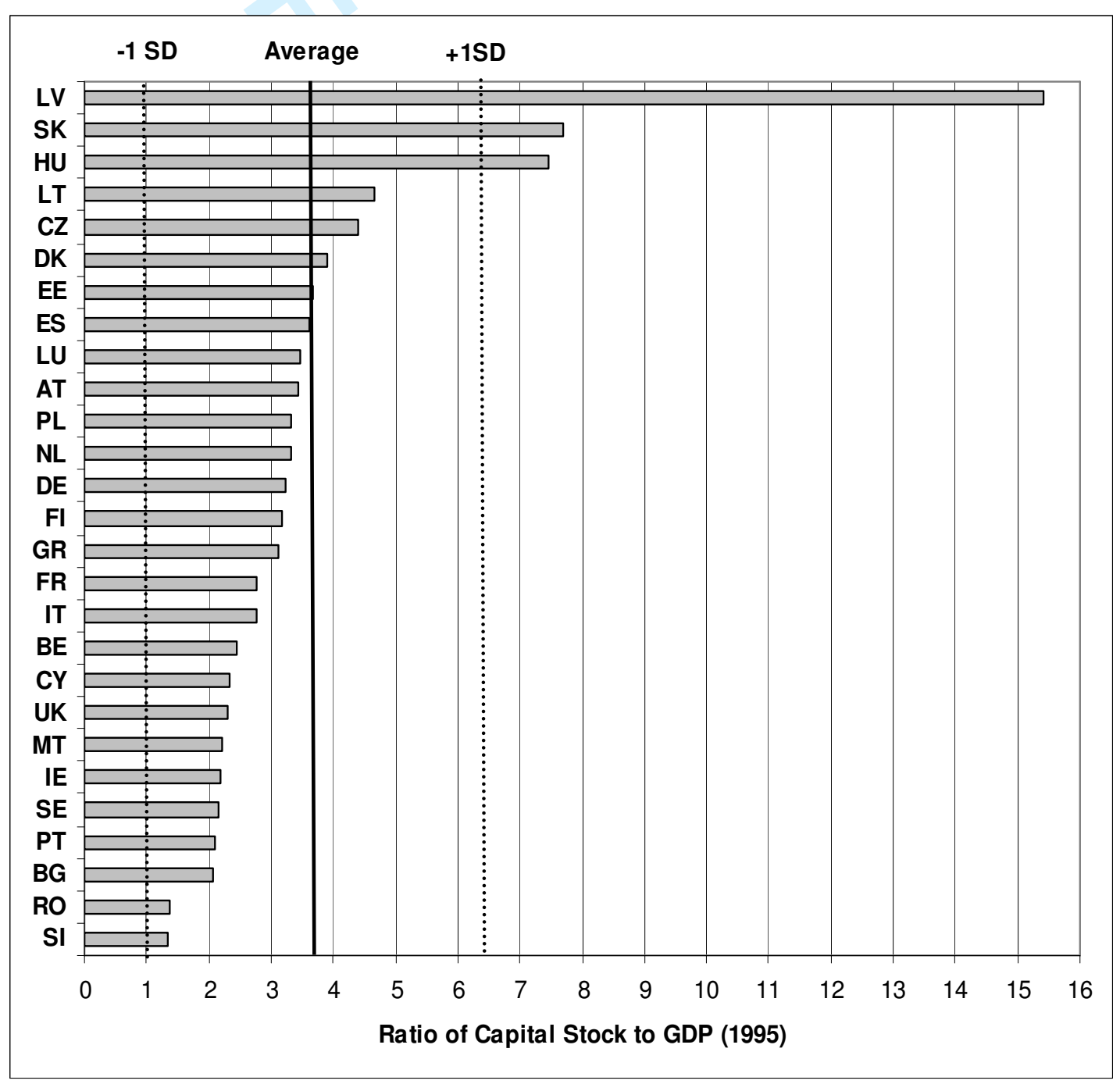


Comparison of NUTS 2 results against other studies

Capital stock estimates are not available at NUTS2 level for most countries. However, estimates for Spain have been produced by the University of Valencia and the Foundation BBVA and are described in Mas et al, 2006. Fig. 3 shows a comparison between the new estimates and those from Mas et al, 2006.

Fig. 3. Comparison of regional estimates for Spain

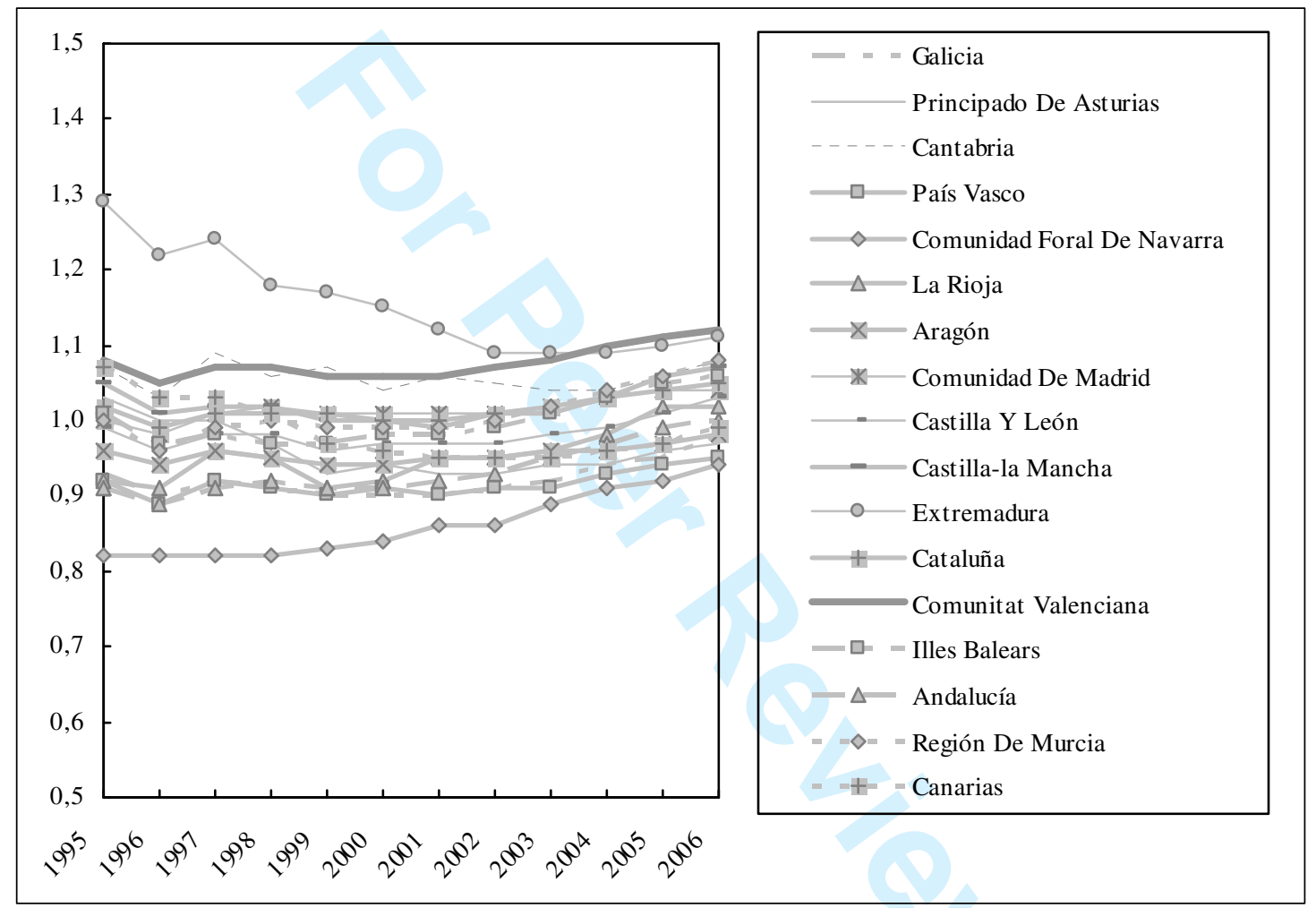

The comparison is carried out by taking the ratio of the Mas et al, 2006, estimates to those of the estimates produced for this project, ie if the ratio is unity then the estimates exactly match, greater than unity indicates that the new estimates are lower than those of Mas et al, 2006. The resulting ratios become quite similar over time. This convergence is expected because, as stated above, as the calculation period is extended any errors introduced as part of the base-year estimation for 1995 are gradually removed from the capital stock through depreciation, and new investment therefore accounts for an increasing proportion of the stock over time. 
Regional results

Net capital stocks across Europe. The real net capital stock by European NUTS2 region is shown in Fig. 4.

Fig. 4: Real net capital stock in Europe in 2007

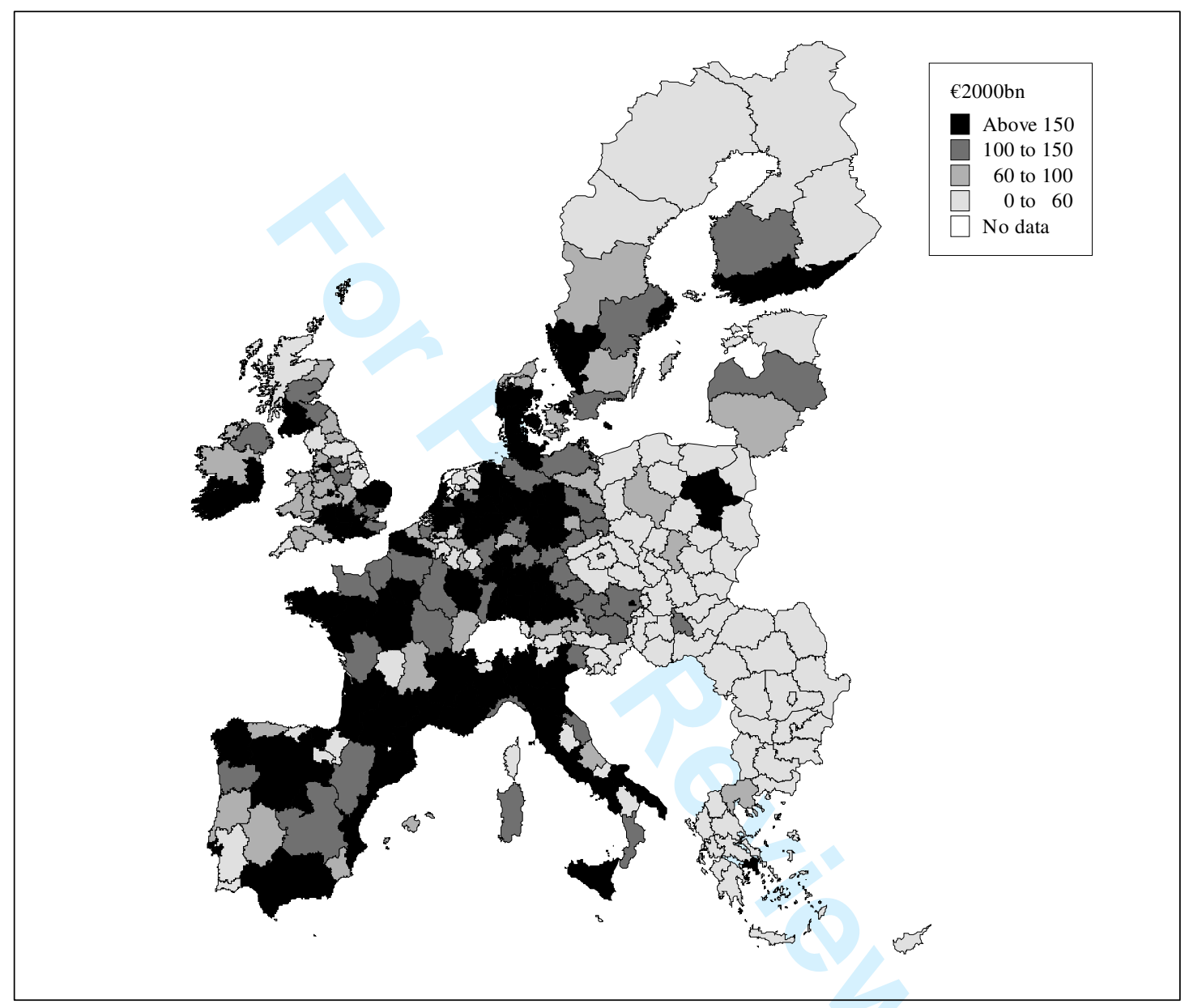

The estimates correspond with what might intuitively be expected: the capital stock is generally higher in Western Europe than in the east, with the exception of the region surrounding Warsaw in central Poland. A large amount of capital is concentrated in the highly industrialised north western part of Germany, as well as in the south western part of the country around Frankfurt. A high level of net capital stock runs the length of Italy but is generally more concentrated in its north. Some results, eg the Andalusia region of Spain and Sicily in Italy, may seem less 
intuitive than expected but further examination has revealed this is due to the scale effect of the size of capital stock in these countries in relation to that of many of the smaller Member States.

Capital-labour ratio. The capital-labour ratio is a useful economic indicator which should be higher in the more well-developed Member States whereas for those areas where labour is relatively less expensive a lower ratio prevails, as stated previously. It can be easily shown that that, under certain assumptions, the capital-output ratio is broadly linked to average labour productivity. The relationship between these ratios can be illustrated formally using a CobbDouglas production function, show in Equation 6 below:

$Q_{t}=A_{t} K_{t}^{\alpha} L_{t}^{1-\alpha}$

Here, $\mathrm{Q}$ is output, $\mathrm{K}$ is capital, $\mathrm{L}$ is labour, and $\mathrm{A}$ represents technology, ie the way in which production possibilities change through time through the development of new inventions and techniques for production. The technology factor is sometimes known as total factor productivity, because it includes all contributions to total production not already reflected in levels of $\mathrm{K}$ and $\mathrm{L}$.

The ratios to be analysed can be derived from the production function shown in Equation 6 as shown in Equations 7, 8 and 9:

$\frac{Q_{t}}{L_{t}}=\frac{A_{t} K_{t}^{\alpha} L_{t}^{1-\alpha}}{L_{t}^{\alpha} L_{t}^{1-\alpha}}$

$\frac{Q_{t}}{L_{t}}=A_{t} \frac{K_{t}^{\alpha}}{L_{t}^{\alpha}}$

$$
\frac{Q_{t}}{L_{t}}=A_{t}\left(\frac{K_{t}}{L_{t}}\right)^{\alpha}
$$

Therefore, labour productivity depends on the level of technology and the capital-labour ratio. 
Fig. 5. Total capital-labour ratio in 2007

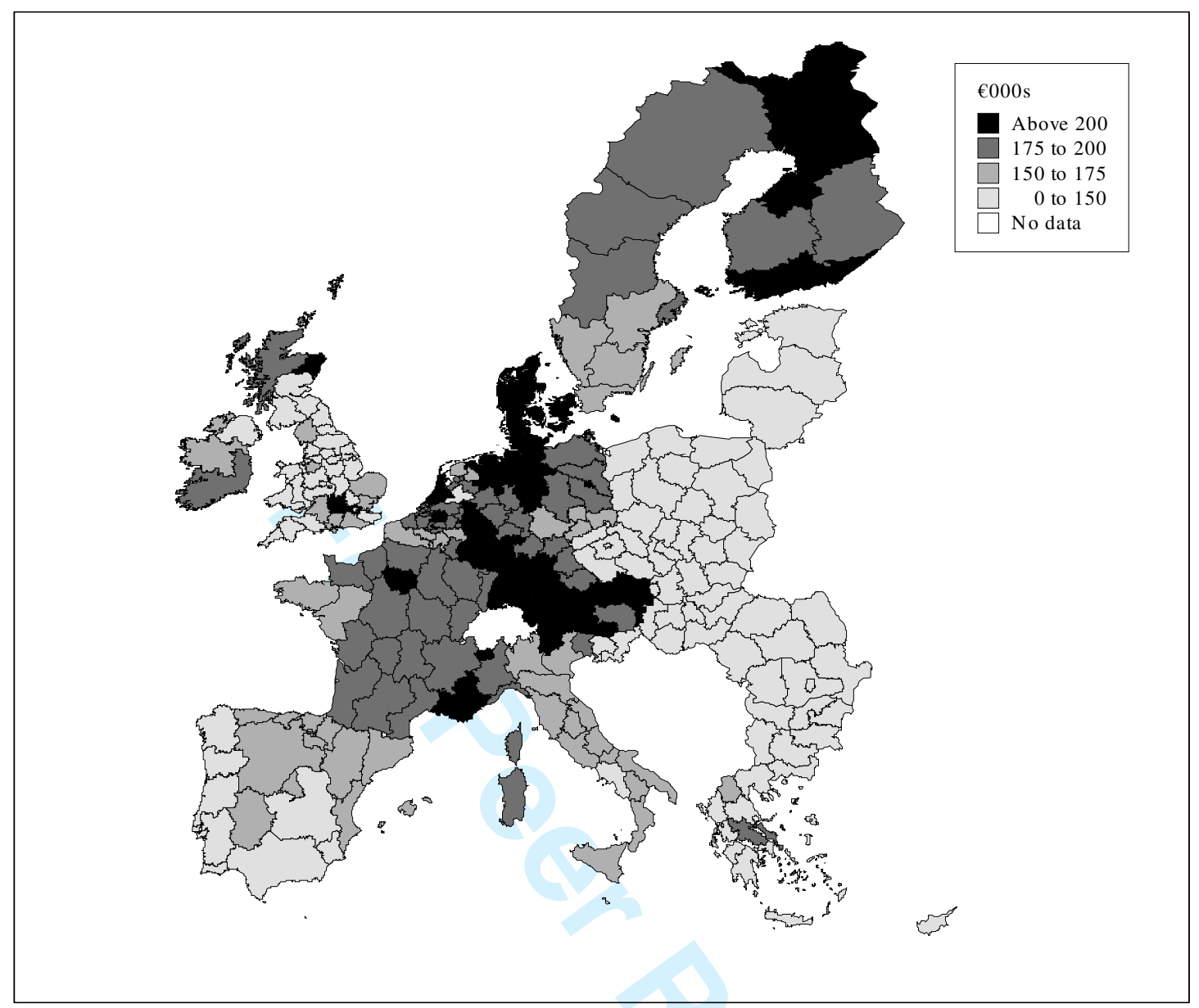

The broad correspondence with expectations shown in Fig. 5 relates to the lower capital-labour ratio in eastern compared with Western Europe, and in northern compared with southern Europe. More specifically, there are clusters of regions with a relatively high capital-labour ratio around the southern parts of Belgium, the South East of England, in the technologicallyadvanced countries of Scandinavia and in northern parts of Germany.

Disaggregating the total capital-labour ratio to show manufacturing only, as in Fig. 6, shows that the same pattern of broad correspondence with expectations with one or two anomalous results again being evident. Some of the Greek NUTS2 regions have an unexpectedly high capital-labour ratio in manufacturing. The unusual method used to construct the Greek baseyear capital stock, as described in the previous section, is likely to explain this. Sardinia also 
has an unexpectedly high capital-labour ratio and the reason for this is less immediately obvious.

Fig. 6. Manufacturing capital-labour ratio in 2007

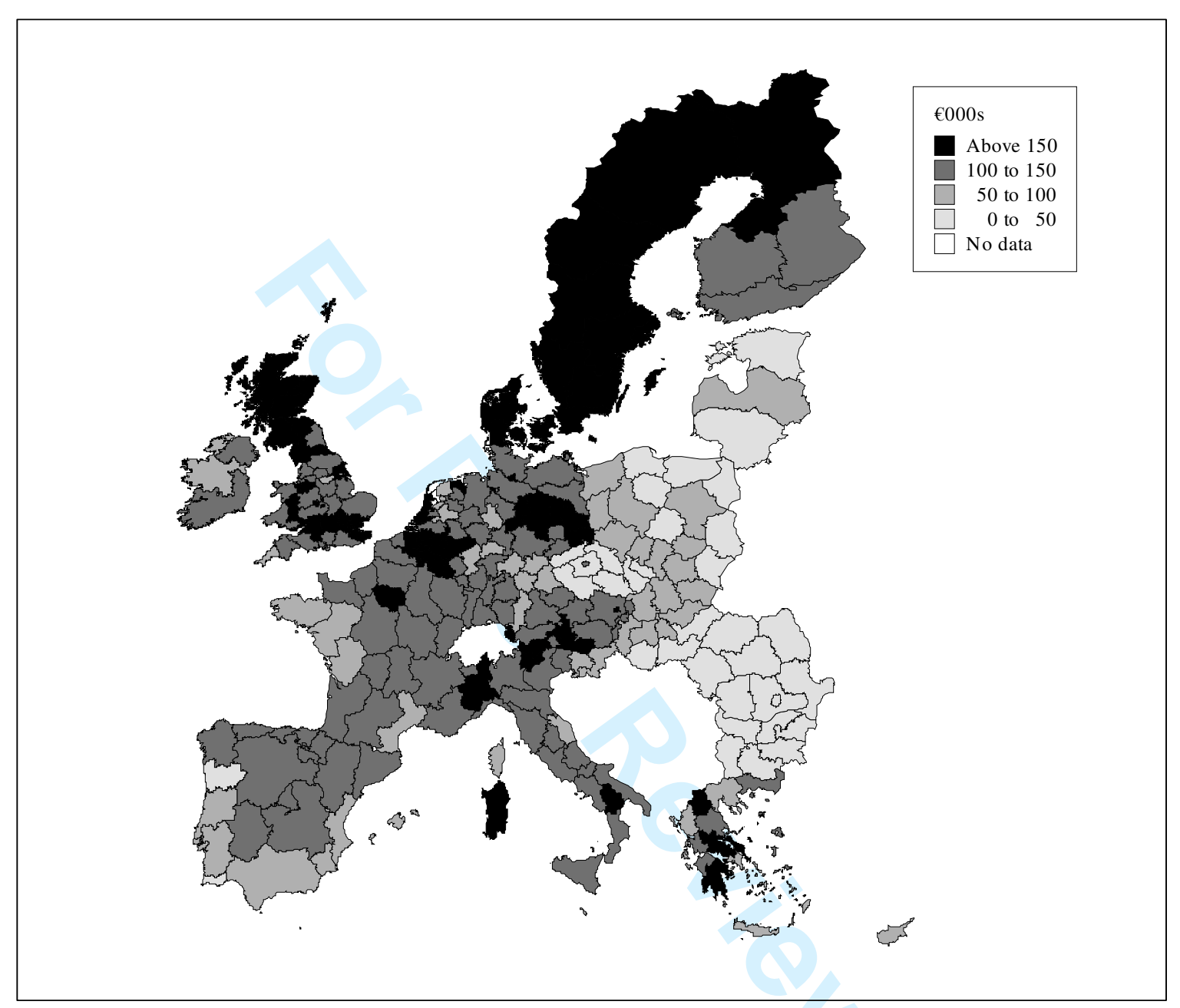

The same broad correspondence with intuitive expectations is also present when examining the capital-labour ratio in services in Fig. 7 but there is probably less variation within countries than may be expected. Across the two identifiable sectors, manufacturing is seen to have a lower capital-labour ratio than services. This is a counter-intuitive result. However, for most countries this anomaly exists in the starting capital stock for 1995 and is therefore a feature of the data rather than the method used to construct estimates. The explanation, or part of it, may lie in the inclusion of the housing stock within the services sector. In the national accounts, the 
value added of the real estate sector includes actual and imputed (for owner-occupiers) rentals for the provision of housing, and the associated capital is the housing stock. Consequently, this activity is highly capital-intensive.

Fig. 7. Services capital-labour ratio in 2007

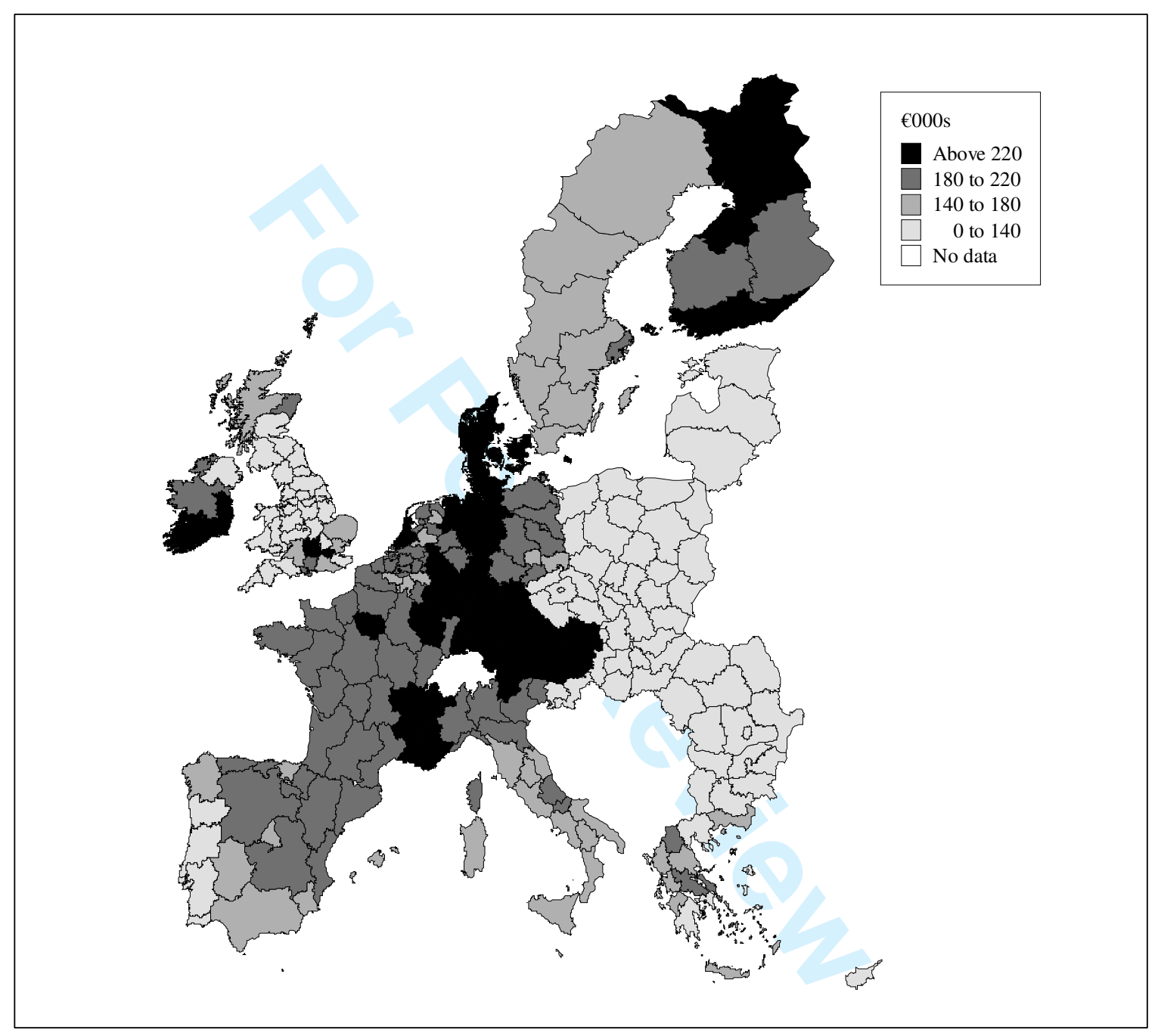

In summary, the ratios examined above commonly exhibit a broad correspondence with intuitive expectations but with a number of obvious exceptions. A further commonality that can be applied is less variation within countries than might be expected. For the majority of the figures this is true of the Eastern European countries in particular, though less variation between the regions of these countries than in Western countries may be expected due to their 
generally lower level of development and their lower labour costs which reduce the incentive to build the capital stock.

\section{Total factor productivity}

As a final use of the new data, a measure of total factor productivity (TFP) was calculated at the regional level. Until now, work on TFP has been restricted to either national level or nationspecific studies where regional capital stocks are created on a more ad-hoc basis. The advantage of a consistent regional capital stock series is that TFP analysis can be undertaken at a lower spatial level across the whole of the EU.

The basic TFP regression is well-known and can be briefly re-capped here. TFP is calculated using a conventional residual approach:

$$
T F P_{i j t}=\exp \left\{\log \left(Y_{i j t}\right)-\alpha \log \left(L_{i j t}\right)-(1-\alpha) \log \left(K_{i j t}\right)\right\}
$$

where:

$\mathrm{Y}_{\mathrm{ijt}}$ is constant price gross value added in region $\mathrm{i}$ for sector $\mathrm{j}$ at time $\mathrm{t}$

$\mathrm{L}$ is total labour input (measured as hours-worked)

$\mathrm{K}$ is the constant price capital stock

$\alpha$ and $(1-\alpha)$ are factor shares which are sometimes estimated by using wages and rates of return, but in this case it has been assumed that $\alpha$ is equal to two-thirds, which is roughly labour's share of production. It should be noted that, as this section is mainly a demonstration of the use of regional capital stocks, it was not considered central to the point to go into too much detail on this topic.

On this basis, aggregate TFP was calculated from 1995 - 2005. Fig. 8 shows the map of TFP across Europe for 2005 and Fig. 9 shows the difference (in pp) between labour productivity growth over 1995-2005 and the equivalent growth in TFP. 
Fig. 8. Total TFP (2005)

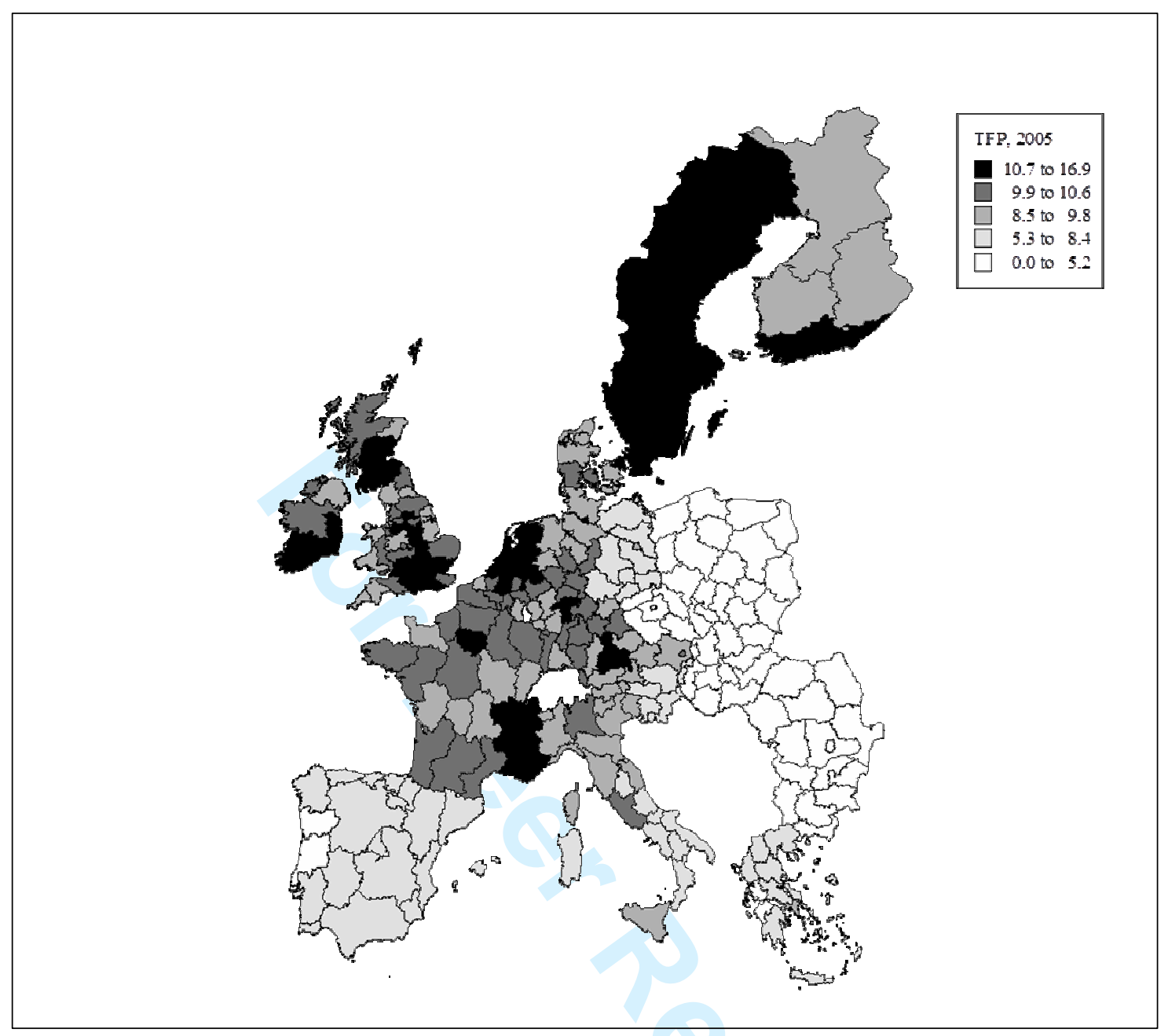

The map of total TFP shows highest levels in the most well-developed regions of Europe, with a standard picture that is now commonplace when looking at indicators of performance. A correlation of average labour productivity with the TFP estimates yields coefficients of 0.98 in levels and 0.93 for growth rates, highlighting the fact that the conditioning of performance against the capital stock does not change the overall picture of regional performance very much. In principle the difference between productivity and TFP growth should reflect the contribution that the capital stock has made to regional performance. In practice this is true, albeit that allowances must be made for the degree of uncertainty surrounding some countries and regions' capital stock measurements. For example, the largest differences shown in Fig. 9 are located around Slovenia, Romania, Portugal and Romania, where the ratio of capital stock 
to GDP seems unusually low from Fig. 2. At the other end of the scale, some negative differences, and those very close to zero, have a high proportion of Latvian and Hungarian regions which seemed to have an over-estimated capital stock from Fig. 2, and possibly little subsequent growth. These are extremes, however, and the majority of regions and countries seem to fit within normal boundaries, highlighting the overall success of the exercise but still pointing to where improvements can be made.

Fig. 9. Labour productivity growth - total TFP growth

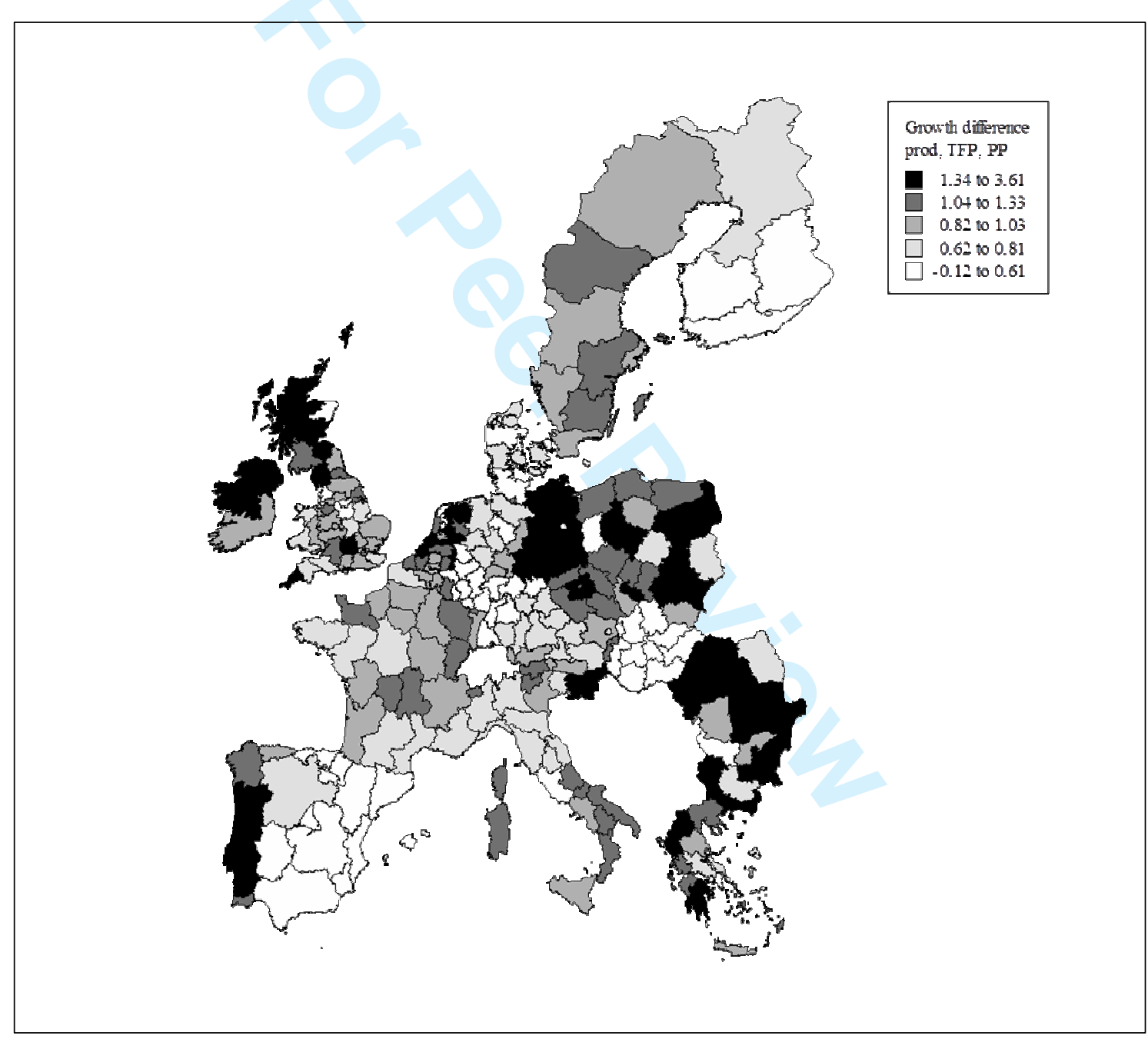




\section{Conclusions and Recommendations}

\section{Summary of findings}

This paper has described a pilot project to assess the feasibility of constructing comparative capital stock statistics at NUTS2 level for the European Union. The estimates are required, among other things, for the European Commission to assist with monitoring the impact of cohesion policies and to identify regions requiring further assistance.

A standard and relatively simple method has been employed as, given the available data, simplicity is required to produce comparable estimates for all NUTS2 regions of the EU. The approach employed was the Perpetual Inventory Method. Under this approach, for any one year the capital stock is essentially a three-way interaction between a revaluation to the current year's prices of the capital stock from the previous year, the depreciation and retirement of capital due to its consumption, and the addition to the stock brought about through investment in this year.

The examinations carried out suggest that the capital stock estimates are broadly robust. Obvious distinctions between the east and west and north and south of Europe are evident, as would be expected. Other results are less expected. Some of these, such as the relatively high capital stock in some parts of Greece, are due to the method used to construct the estimates for those countries. For Greece, Bulgaria and Malta the base-year estimate was constructed based on capital-output ratios from 'similar' countries. There is a European-wide requirement for national statistical offices to produce national estimates of the capital stock. It is being brought into enforcement in phases. Ireland, for example, published capital stock estimates for the fist time at the beginning of 2010 in order to comply with this requirement. The requirement will eventually ensure that all EU countries publish national level estimates. When Bulgaria, Greece and Malta comply it will then be possible to reproduce the estimates for these countries using their national estimates to produce a more robust base-year estimate and, therefore, to improve the statistics for these countries considerably. 
Finally, using the capital stock data to construct a regional TFP indicator seems to yield sensible results, with a strong link to average labour productivity and a broadly expected picture of European regional performance.

The study has been successful in showing that it is possible to produce relatively robust and, crucially, comparable estimates of the capital stock at NUTS2 level for all EU countries. This work has, for the first time, brought into existence regional-level capital stock estimates for the whole of the EU, produced using the same method in each case. They can therefore provide a useful input into policy decision making, assessment of cohesion policies and identification of regions requiring further support. Furthermore, the method employed is sufficiently simple to be replicable and for the statistics to be regularly updatable.

\section{Recommendations}

In summary, to develop and further improve the capital stock statistics produced as part of this report it is recommended that:

- The statistics be updated annually because the further from the base-year the end period of the estimates is (currently 2007), the less impact of any errors introduced as part of the process of creating the base-year estimate because of depreciation and retirement (as mentioned above).

- The estimates for Greece, Bulgaria and Malta should be recalculated using capital stock estimates from each country's national statistical office for the base-year once these become available.

- The base-year capital stock for Latvia was based on an estimate of the capital stock for 2007 from the Latvian national statistical office. However, because only one year of estimates existed, it was necessary to extrapolate these back to 1995 using growth rates from the Lithuanian capital stock. As the Latvian NSO produces more years of estimates these can be used to extrapolate back to 1995 instead.

- Some anomalous results are likely to be caused by the inclusion of the housing stock within the services sector. The value added of the real estate sector includes actual and imputed (for 
owner-occupiers) rentals for the provision of housing, and the associated capital is the housing stock. This is included in the services sector resulting in it having a higher level of capital stock than manufacturing. If a way could be found to disaggregate this out from services then this would improve the results. However, there is currently no basis on which to do this.

\section{References}

Aghion P and Howitt P (1999) Endogenous growth theory, MIT Press: Cambridge Mass. Maddison, A.M. (1992) Standardised Estimates of Fixed Investment and Capital Stock at Constant Prices: a Long Run Survey for 6 Countries, Paper for the 22nd General Conference of the International Association for Research in Income and Wealth (IARIW), Flims, Switzerland. Mas, M., Perez, F. and Uriel, E. (2000) Estimation of the Stock of Capital in Spain, Review of Income and Wealth, Series 46(1).

Mas, M., Perez, F. and E. Uriel (2006), Capital Stock in Spain, 1964-2002. New estimates, Fundaciôn BBVA, Bilbao.

NIESR (2002) http://www.niesr.ac.uk/event/productivity.PPT\#4, accessed 15/07/2010.

OECD Manual (2001), Measuring capital: Measurement of capital stocks, consumption of fixed capital and capital services, Paris.

OECD Manual (2009), Measuring capital. Paris: OECD (http://www.olis.oecd.org/olis/2009doc.nsf/LinkTo/NT00000962/\$FILE/JT03258144.PDF)

Ward, M. (1976), The measurement of capital: The methodology of capital stock estimates in OECD countries. Paris: OECD. 